\title{
Brain derived neurotrophic factor moderates associations between maternal smoking during pregnancy and offspring behavioral disorders
}

\author{
Ardesheer Talati ${ }^{\mathrm{a}, \mathrm{b}, \mathrm{e}, *}$, Zagaa Odgerel $^{\mathrm{b}}$, Priya J. Wickramaratne ${ }^{\mathrm{a}, \mathrm{b}, \mathrm{d}}$, \\ Myrna M. Weissman a,b,c,e \\ ${ }^{a}$ Department of Psychiatry, Columbia University Medical Center, New York, NY, USA \\ b Division of Epidemiology, New York State Psychiatric Institute, New York, NY, USA \\ ${ }^{\mathrm{c}}$ Departments of Epidemiology, Mailman School of Public Health of Columbia University, New York, NY, USA \\ d Departments of Biostatistics, Mailman School of Public Health of Columbia University, New York, NY, USA \\ e Sackler Institute for Developmental Psychobiology, Columbia University, New York, NY, USA
}

\section{A R T I C L E I N F O}

\section{Article history:}

Received 29 April 2016

Received in revised form

25 August 2016

Accepted 27 August 2016

Available online 28 August 2016

Keywords:

In utero exposure

val66met

\begin{abstract}
A B S T R A C T
Maternal smoking during pregnancy is associated with a number of adverse offspring outcomes. In the present study, based on 209 offspring from a 3-generation family study of depression, we show that the effects of prenatal exposure on offspring externalizing psychopathology (conduct, substance use disorder) is more pronounced in the presence of lower-expressing brain derived neurotrophic factor (BDNF) gene variants. BDNF plays an important role in the development and survival of neural circuits. Individuals with low-expressing variants who are further exposed to prenatal tobacco smoke may be most vulnerable to a spectrum of behavioral disorders that depend on these circuits.
\end{abstract}

(c) 2016 Elsevier Ireland Ltd. All rights reserved.

\section{Introduction}

Smoking during pregnancy is a leading cause of preventable illness among pregnant mothers and their offspring (CDC, 2006a, 2006b). The fetus is particularly vulnerable, as numerous tobacco components not only traverse the placenta, but, with chronic exposure, can reach higher levels in the fetus than in the mother (Lambers and Clark, 1996; Rogers, 2009). Offspring problems begin early, in the form of pregnancy-related complications and lower birthweight (DiFranza and Lew, 1995; Kallen, 2001). They continue as the offspring age through childhood and adolescence, with reported increases in a range of behavioral problems and disorders (Nomura et al., 2011; O'Callaghan et al., 2009; Wakschlag et al., 2002). Not all exposed offspring go on to develop these problems, however. Searching for factors that moderate the risks conferred by prenatal exposure can help understand mechanistic pathways and identify offspring groups at greatest risk, so they can be targeted for early intervention.

\footnotetext{
* Correspondence to: Department of Psychiatry, New York State Psychiatric Institute, 1051 Riverside Drive, Unit 24, New York, NY 10032, USA.

E-mail addresses: talatia@nyspi.columbia.edu, at2071@cumc.columbia.edu (A. Talati),zdodgerel@yahoo.com (Z. Odgerel), wickramp@nyspi.columbia.edu (P.J. Wickramaratne), mmw3@columbia.edu (M.M. Weissman).
}

Neural growth factors are attractive candidates within this framework as they, like the cholinergic receptors to which nicotine binds, are ubiquitously expressed in the brain and active during fetal development in promoting cell growth and survival (Groves, 2007; Lu et al., 2005). Brain derived neurotrophic factor (BDNF) is the most ubiquitous example, and is of particular interest from a genetic perspective given demonstrated functional consequences of variation within its gene: a polymorphism that substitutes a nucleotide encoding valine to one encoding methionine (val66met) results in decreased gene expression and activity-dependent secretion (Chen et al., 2006; Egan et al., 2003). Mice with BDNF deletions show impaired learning and spatial memory (Heldt et al., 2007, 2014), as well as disruptions in GABAergic and cholinergic neurons (Grosse et al., 2005). In human studies, lower BDNF levels have also been linked to reduced cortical thickness (Legge et al., 2015; Wang et al., 2014). Prenatal exposure to tobacco has been further associated with lower levels of BDNF mRNA and proteins in rodents (Yochum et al., 2014) and with higher gene methylation in humans (Toledo-Rodriguez et al., 2010). In adult smokers, chronic smoking is also correlated with BDNF protein levels (Bhang et al., 2010; Bus et al., 2011).

We use an existing longitudinal family study of depressive disorders to test whether BDNF moderates the effect of exposure to tobacco on childhood and adolescent psychopathology, hypothesizing that offspring with both genetic (met-encoding BDNF 
variants) and environmental (exposure to maternal smoking in pregnancy) risks will have higher rates of internalizing and externalizing psychopathology than offspring with one or neither of these risks.

\section{Methods}

\subsection{Sample}

Design and clinical procedures have been detailed previously (Weissman et al., 1999, 2006, 2005). Briefly, depressed probands were selected from outpatient clinics for treatment of mood disorders; non-depressed probands were selected concurrently from an epidemiological sample from the same community. The probands, along with their children (G2) were followed longitudinally for six waves up to 30 years. At the third wave (year 10), grandchildren (G3) were also directly interviewed. Procedures were kept similar across waves to avoid method variation bias. Procedures were approved by the New York State Psychiatric Institute's Institutional Review Board, and informed consent was obtained from all study participants.

Prenatal histories were collected on 389 participants. Of these, $378(97 \%)$ offspring were directly interviewed at least once, and 209 (55\%) provided DNA. Participants with and without DNA did not vary by exposure status [among the genotyped subset, $27 \%$ were exposed; among the non-genotyped, $29 \%$ were exposed, $\left.\chi^{2}=0.22, \mathrm{p}=0.63\right]$.

\subsection{Assessments}

Mothers (G1 mothers, for G2 offspring, and G2 mothers for G3 offspring) completed a report for each child that included questions about the course of pregnancy and delivery. For G2 offspring, They were asked whether they had smoked while pregnant, and if so, how frequently they had smoked $\geq 10$ cigarettes per day: [1-2 times/3-5 times/6-10 times/every two weeks/weekly/daily or almost daily]. Because most ( $>98 \%$ ) mothers reported either not smoking at all or smoking daily, we generated a dichotomous variable based on whether or not the mother reported smoking $\geq 10$ cigarettes/day, almost every day. Similar cutoffs are used in other studies (Cornelius et al., 2000; Hoff et al., 1986).

Offspring were assessed using the age-appropriate version of the semi-structured Schedule for Affective Disorders and Schizophrenia interview (Kaufman et al., 1997; Mannuzza et al., 1986), administered by trained doctoral- and masters-level mental health professionals, blind to prenatal exposure or parental history. The first interview assessed the lifespan until that interview; subsequent interviews assessed intervening time periods. The total assessment period, therefore, is cumulative to the year of final interview. Final diagnoses were made using the best-estimate procedure (Leckman et al., 1982). Inter-rater reliability was high (Weissman et al., 1999).

\subsection{Genotyping}

Val66met (rs6265) was genotyped using DNA from blood samples, with Taqman technology (Applied Biosystems, Foster City, CA). Assays were made as follows in $5 \mu \mathrm{l}$ reaction volume: $10 \mathrm{ng} / \mu \mathrm{l}$ DNA dried down, $1 \mathrm{X}$ Applied Biosystems Taqman Universal PCR MasterMix, 0.5X Taqman assay mix. The reaction was cycled for 1 cycle of $95{ }^{\circ} \mathrm{C}$ for $10 \mathrm{~min}$., and 50 cycles of $92{ }^{\circ} \mathrm{C}$ for $15 \mathrm{~s}$, and $60^{\circ} \mathrm{C}$ for $60 \mathrm{~s}$ on an Applied Biosystems GeneAmp PCR System 9700. Genotypes were read on Applied Biosystems 7900 using SDS 2.1 software.

\subsection{Statistical analysis}

Data were analyzed using Statistical Analysis Software (SAS 9.0/ Carey NC). Outcome, genetic, and exposure variables were categorized as dichotomous variables. Group comparisons were conducted using chi-square tests. Consistent with other studies (Lang et al., 2007; Montag et al., 2008), we compared offspring with $\geq 1$ copy of the met-encoding allele to those with $\mathrm{val} / \mathrm{val}$. To test the hypothesis that genotype moderates the association between prenatal smoke exposure and psychopathology, we used a Breslow-Day Test for Homogeneity of Odds Ratios (Breslow and Day, 1980). This tests the null hypothesis that the odds ratio representing the association between smoke exposure and disorder is the same across different genotypes. Finally, we modeled the effects of prenatal exposure and genotype on each significant outcome using logistic regression within a generalized estimating equations approach (Hardin and Hilbe, 2003) [PROC GENMOD] to account for potential within-family correlations. Exposure and offspring genotype were the predictor variables, and age, gender, and maternal depression and substance use history as covariates. To test whether the effects of exposure on outcome varied significantly by genotype, we included a gene-by-exposure interaction term in the model.

\section{Results}

Sample characteristics are summarized in e-Table 1. Mothers who smoked during pregnancy were more likely to have lifetime major depression or substance use disorder. However there were no other parental or demographic differences between offspring exposed versus unexposed offspring, or between the offspring with risk versus non-risk encoding genotypes. Genotype and exposure were also not independently associated with each other (43\% exposed, as compared to $33 \%$ unexposed, offspring had $\geq 1$ met allele $\left(\chi^{2}=2.17, p=0.14\right)$ ).

We examined associations between exposure and outcome within each genotype group (Table 1). Among offspring with val/ val encoding genotypes, there was no significant association between exposure to maternal smoking and any offspring outcome (left columns), except substance use disorders, where exposure reduced the rates of substance use. Among offspring with $\geq 1$ met alleles, however, prenatal exposure was associated with higher rates of offspring externalizing disorders, particularly conduct (52 vs $22 \%$ ) and substance use ( 72 vs $41 \%$ ) disorders (there were no associations with casual drug or alcohol use). Genotype $\times$ exposure comparisons to formally test whether associations between exposure and outcome varied by genotype revealed significant interactions for externalizing disorder (right-most column, $\mathrm{p}=0.0097)$, which were largely accounted for by substance use $(\mathrm{p}=0.0009)$ and conduct $(\mathrm{p}=0.01)$ disorders. There were no significant associations for internalizing disorders, although a trend was noted for major depression.

We next tested the above findings in a model that further accounted for offspring age and sex, maternal depression and substance use, and the potential non-independence of outcomes within families. As shown in Table 2, a significant overall genotype by exposure interaction was detected for externalizing disorders $(\mathrm{p}=0.019)$, which was driven by substance use $(\mathrm{p}=0.0023)$ and conduct $(p=0.017)$, but not internalizing disorders. Among the other included covariates, having a familial history of depression, being female, and being older, each increased the overall risk for having an internalizing disorder; conversely, being male was associated with higher rates of having an externalizing disorder.

When we restricted the sample to the second generation offspring, exposure $\times$ genotype interactions remained significant 
Table 1

Exposure effects based on genotype.

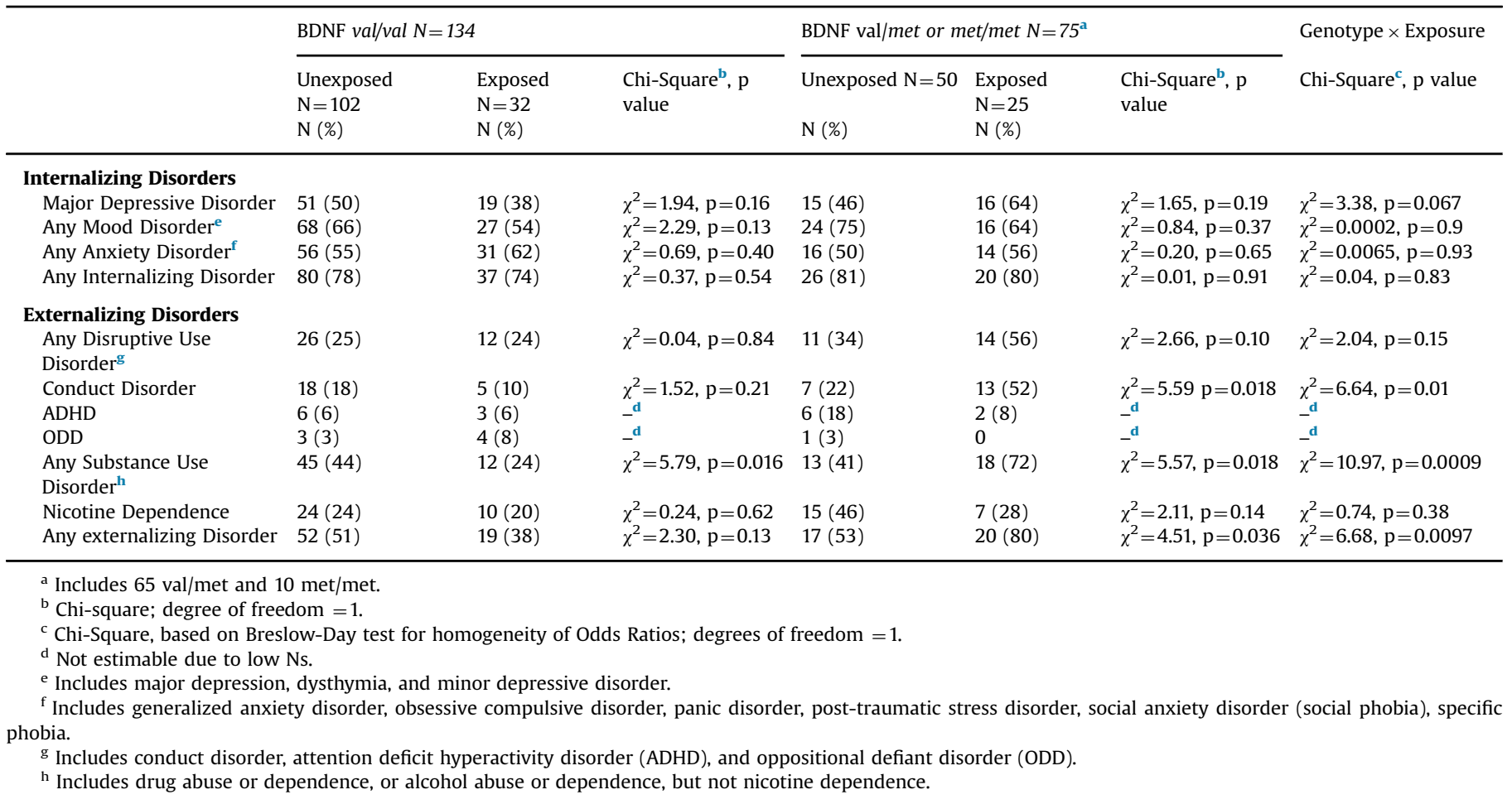

(conduct, $\beta=1.97$ (s.e. $=0.081$ ), $\mathrm{p}=0.016$; substance use, $\beta=3.05$ (0.86), $\mathrm{p}=0.006)$. We could not restrict the sample to the 3rd generation, as the analytic sample was too small.

\section{Discussion}

BDNF moderated associations between maternal smoking during pregnancy and offspring externalizing psychopathology. BDNF genotype was not independently related to exposure. Though primarily linked to anxiety- and depressive-phenotypes, a role for BDNF in substance use and related psychopathology (Beuten et al., 2005; Lang et al., 2007; Shin et al., 2010) has also been suggested, though findings are inconsistent (Groves, 2007; Montag et al., 2008).

Reduced BDNF efficiency may promote vulnerability to addiction or other disorders of executive control by suppressing firing of inhibitory neurons, thereby decreasing the brain's ability to downregulate excitatory circuits (Hong et al., 2008; Sakata et al., 2009). Nicotine exposure, particularly during vulnerable fetal development, may compound these problems by epigenetically modifying and silencing BNDF. Val carriers may have greater flexibility to respond to environmental insults with renewed cell growth because of their larger reserves of the neurotrophin; met carriers, already programmed for lower expression, may be more vulnerable. This hypothesis is supported by other work showing val carriers to be more resilient to depressive illness following childhood maltreatment than their met counterparts (Kaufman et al., 2006), as well as animal studies showing that over-expression of BDNF confers resilience to anxiety-related behaviors (Govindarajan et al., 2006).

Although the full mechanisms through which gestational perturbations might influence later child- or adolescent outcomes are not fully appreciated, epigenetic modifications of nerve growth factors may be one source. Studies have shown alterations in methylation of a number of key regulatory genes, among offspring exposed to tobacco in utero (Nielsen et al., 2016; Terry et al., 2008). Furthermore, these changes are observed across different cell types and even though they abate over time, appear to persist through early development (Zeilinger et al., 2013). Though a number of studies have examined other genes [see (Nielsen et al., 2016) for review], only study to our knowledge directly examined effects of maternal prenatal smoking on offspring BDNF methylation. That study showed that prenatal exposure increased the rate of methylation in the promoter region of BDNF-6 exon and 5' untranslated regions (Toledo-Rodriguez et al., 2010). Although methylation differences did not account for higher rates of drug use in exposed offspring, but that could be because only one outcome was assessed (no. of drugs tried), offspring were still young (age range, 13-16), and the study was restricted to offspring with the more efficient ( $\mathrm{val}$ encoding) genotype. Although these observations do not establish that exposure to maternal smoking causes such changes, they suggest one potential path through which early perturbations can disrupt cortical development in ways having long-term effects.

There are a number of strengths to the present study, including the longitudinal design (which allowed collection of exposure variable prior to onset of disease), long-term offspring follow-up blind to maternal assessment, and multiple clinical outcomes. There are also limitations. The sample is modest for genetic studies, and findings require independent replication. Because of the sample size, we could not further examine gender- or generationspecific effects. It is also possible that some mothers under-reported use. However, this would have decreased rather than inflated results. Because of the design and the high baseline rates of psychopathology, associations may not generalize to the population. Causal interpretations are unwarranted, as other unmeasured behavioral or biological variables could account for the relationships observed. Although all subjects were Caucasian, we cannot rule out further population sub-stratification.

The findings suggest that offspring exposed to maternal smoking and have the risk variant at BDNF are a high-risk group 
Table 2

Main and interactive effects of prenatal exposure and BDNF genotype on offspring. (Psychiatric disorders)

\begin{tabular}{|c|c|c|c|}
\hline Outcome & Covariates: & $\begin{array}{l}\text { Estimate (s. } \\
\text { e.) }\end{array}$ & $P$ value \\
\hline \multirow[t]{7}{*}{ Major Depression } & Exposure & $-0.29(0.42)$ & 0.48 \\
\hline & Genotype & $-0.55(0.37)$ & 0.13 \\
\hline & $\begin{array}{l}\text { Exposure } \times \text { Genotype } \\
\text { Interaction }\end{array}$ & $1.31(0.68)$ & 0.055 \\
\hline & Maternal Depression & $1.24(0.31)$ & 0.0001 \\
\hline & Sex & $0.67(0.30)$ & 0.024 \\
\hline & Age & $0.03(0.01)$ & 0.0097 \\
\hline & Maternal Substance Use & $-0.54(0.33)$ & 0.097 \\
\hline \multirow[t]{7}{*}{ Any Mood Disorder } & Exposure & $0.26(0.47)$ & 0.57 \\
\hline & Genotype & $-0.59(0.37)$ & 0.11 \\
\hline & $\begin{array}{l}\text { Exposure } \times \text { Genotype } \\
\text { Interaction }\end{array}$ & $0.05(0.71)$ & 0.94 \\
\hline & Maternal Depression & $1.02(0.31)$ & 0.0011 \\
\hline & Sex & $0.59(0.30)$ & 0.054 \\
\hline & Age & $0.04(0.01)$ & 0.017 \\
\hline & Maternal Substance Use & $0.29(0.33)$ & 0.37 \\
\hline \multirow[t]{7}{*}{ Any Anxiety Disorder } & Exposure & $-0.33(0.42)$ & 0.43 \\
\hline & Genotype & $0.28(0.37)$ & 0.44 \\
\hline & $\begin{array}{l}\text { Exposure } \times \text { Genotype } \\
\text { Interaction }\end{array}$ & $0.01(0.67)$ & 0.98 \\
\hline & Maternal Depression & $0.95(0.31)$ & 0.0021 \\
\hline & Sex & $0.84(0.29)$ & 0.0043 \\
\hline & Age & $\begin{array}{l}-0.001 \\
(0.01)\end{array}$ & 0.91 \\
\hline & Maternal Substance Use & $0.42(0.32)$ & 0.19 \\
\hline \multirow{7}{*}{$\begin{array}{l}\text { Disruptive behavior } \\
\text { Disorder }\end{array}$} & Exposure & $0.36(0.44)$ & 0.42 \\
\hline & Genotype & $-0.02(0.41)$ & 0.96 \\
\hline & $\begin{array}{l}\text { Exposure } \times \text { Genotype } \\
\text { Interaction }\end{array}$ & $0.86(0.69)$ & 0.21 \\
\hline & Maternal Depression & $0.45(0.34)$ & 0.18 \\
\hline & Sex & $-0.39(0.31)$ & 0.20 \\
\hline & Age & $0.01(0.01)$ & 0.49 \\
\hline & Maternal Substance Use & $0.83(0.33)$ & 0.013 \\
\hline \multirow[t]{7}{*}{ Conduct Disorder } & Exposure & $0.15(0.51)$ & 0.76 \\
\hline & Genotype & $-0.59(0.54)$ & 0.27 \\
\hline & $\begin{array}{l}\text { Exposure } \times \text { Genotype } \\
\text { Interaction }\end{array}$ & $1.92(0.81)$ & 0.017 \\
\hline & Maternal Depression & $0.75(0.42)$ & 0.077 \\
\hline & Sex & $-0.42(0.36)$ & 0.25 \\
\hline & Age & $0.04(0.02)$ & 0.018 \\
\hline & Maternal Substance Use & $0.52(0.38)$ & 0.17 \\
\hline \multirow{7}{*}{$\begin{array}{l}\text { Substance Use } \\
\text { Disorder }\end{array}$} & Exposure & $-0.21(0.42)$ & 0.62 \\
\hline & Genotype & $-0.85(0.39)$ & 0.029 \\
\hline & $\begin{array}{l}\text { Exposure } \times \text { Genotype } \\
\text { Interaction }\end{array}$ & $2.14(0.70)$ & 0.0023 \\
\hline & Maternal Depression & $0.28(0.31)$ & 0.37 \\
\hline & Sex & $-0.74(0.29)$ & 0.012 \\
\hline & Age & $0.017(0.01)$ & 0.19 \\
\hline & Maternal Substance Use & $0.27(0.32)$ & 0.39 \\
\hline \multirow[t]{7}{*}{ Nicotine Dependence } & Exposure & $0.97(0.44)$ & 0.028 \\
\hline & Genotype & $-0.10(0.44)$ & 0.19 \\
\hline & $\begin{array}{l}\text { Exposure } \times \text { Genotype } \\
\text { Interaction }\end{array}$ & $-0.87(0.73)$ & 0.81 \\
\hline & Maternal Depression & $0.87(0.37))$ & 0.23 \\
\hline & Sex & $-0.74(0.33)$ & 0.019 \\
\hline & Age & $0.007(0.014)$ & 0.96 \\
\hline & Maternal Substance Use & $0.65(0.35)$ & 0.067 \\
\hline
\end{tabular}

Co-variates were coded as follows:

Exposure compares exposure to $\geq 10$ cigarettes per day in pregnancy vs. not.

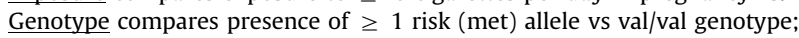

Maternal depression compares lifetime maternal depression to no depression.

Sex compares female vs male.

Age is encoded as a continuous variable.

Maternal substance use compares maternal lifetime substance use disorder to no disorder.

Positive beta estimates indicate a positive effect of the corresponding covariate, as coded above. A positive value for the interaction term indicates that the association between exposure and diagnosis was greater among offspring with $\geq 1$ met allele, as compared to those with no met alleles. for long-term psychopathology, and may benefit from earlier or more regular screening. But this is a preliminary study, and we caution against over-interpretation. BDNF genotype may be static, but its expression and function are highly modifiable by cellular processes, interactions with other genes and environments, location in the brain, and maturity of gene product (Lu et al., 2005; Martinowich and Lu, 2008). Smoking can also modulate BDNF levels in adulthood above and beyond the effects of prenatal exposure (Kim et al., 2007).

This one interaction should be viewed as an example rather than summary. Ultimately, contributions of genetic polymorphisms will be better addressable using large studies with assessments of multiple biological and environmental factors through the life course.

\section{Funding}

The study is funded in part by grants from the National Institute of Mental Health (2R01 MH36197, Weissman PI, and 5P50 MH090966, Gingrich/Weissman, PIs), National Institute of Drug Abuse (1K01 DA029598, Talati, PI), NARSAD Young Investigator Awards from the Brain and Behavior Research Foundation (Talati, PI) and the Sackler Institute for Developmental Psychobiologyand diagnosis was greater among offspring with $\geq 1$ met allele, as compared to those with no met alleles.

\section{Declaration of interest}

The authors have no financial disclosures or conflicts of interest to declare.

\section{Appendix A. Supplementary material}

Supplementary data associated with this article can be found in the online version at http://dx.doi.org/10.1016/j.psychres.2016.08. 061.

\section{References}

Beuten, J., Ma, J.Z., Payne, T.J., Dupont, R.T., Quezada, P., Huang, W., et al., 2005. Significant association of BDNF haplotypes in European-American male smokers but not in European-American female or African-American smokers. Am. J Med. Genet. B Neuropsychiatr. Genet. 139B, 73-80.

Bhang, S.Y., Choi, S.W., Ahn, J.H., 2010. Changes in plasma brain-derived neurotrophic factor levels in smokers after smoking cessation. Neurosci. Lett. 468, 7-11.

Breslow, N.E., Day, N.E., 1980. Statistical methods in cancer research. Volume I - The analysis of Case-Control Studies. IARC Sci Publ, pp. 5-338.

Bus, B.A., Molendijk, M.L., Penninx, B.J., Buitelaar, J.K., Kenis, G., Prickaerts, J., et al., 2011. Determinants of serum brain-derived neurotrophic factor. Psychoneuroendocrinology 36, 228-239.

CDC, 2006a. Maternal and Infant Health: Smoking During Pregnancy Atlanta. Centers for Disease Control and Prevention, Department of Health and Human Services, GA.

CDC, 2006b. Preventing Chronic Diseases: Investing Wisely in Health Bethesda. Centers for Disease Control and Prevention, US Department of Health and Human Services, MD.

Chen, Z.Y., Jing, D., Bath, K.G., Ieraci, A., Khan, T., Siao, C.J., et al., 2006. Genetic variant BDNF Val66Met polymorphism alters anxiety-related behavior. Science 314, 140-143.

Cornelius, M.D., Leech, S.L., Goldschmidt, L., Day, N.L., 2000. Prenatal tobacco exposure: is it a risk factor for early tobacco experimentation? Nicotine Tob. Res 2 45-52.

DiFranza, J.R., Lew, R.A., 1995. Effect of maternal cigarette smoking on pregnancy complications and sudden infant death syndrome. J. Fam. Pract. 40, 385-394.

Egan, M.F., Kojima, M., Callicott, J.H., Goldberg, T.E., Kolachana, B.S., Bertolino, A., et al., 2003. The BDNF val66met polymorphism affects activity-dependent secretion of BDNF and human memory and hippocampal function. Cell 112, 
257-269.

Govindarajan, A., Rao, B.S., Nair, D., Trinh, M., Mawjee, N., Tonegawa, S., et al., 2006. Transgenic brain-derived neurotrophic factor expression causes both anxiogenic and antidepressant effects. Proc. Natl. Acad. Sci. USA 103, 13208-13213.

Grosse, G., Djalali, S., Deng, D.R., Holtje, M., Hinz, B., Schwartzkopff, K., et al., 2005. Area-specific effects of brain-derived neurotrophic factor BDNF genetic ablation on various neuronal subtypes of the mouse brain. Brain Res. Dev. Brain Res. 156, $111-126$.

Groves, J.O., 2007. Is it time to reassess the BDNF hypothesis of depression? Mol. Psychiatry 12, 1079-1088.

Hardin, J.W., Hilbe, J.M., 2003. Generalized Estimating Equations Boca Raton. Chapman and Hall, FL.

Heldt, S.A., Stanek, L., Chhatwal, J.P., Ressler, K.J., 2007. Hippocampus-specific deletion of BDNF in adult mice impairs spatial memory and extinction of aversive memories. Mol. Psychiatry 12, 656-670.

Heldt, S.A., Zimmermann, K., Parker, K., Gaval, M., Weinshenker, D., Ressler, K.J., 2014. BDNF deletion or TrkB impairment in amygdala inhibits both appetitive and aversive learning. J. Neurosci. 34, 2444-2450.

Hoff, C., Wertelecki, W., Blackburn, W.R., Mendenhall, H., Wiseman, H., Stumpe, A., 1986. Trend associations of smoking with maternal, fetal, and neonatal morbidity. Obstet. Gynecol. 68, 317-321.

Hong, E.J., McCord, A.E., Greenberg, M.E., 2008. A biological function for the neuronal activity-dependent component of Bdnf transcription in the development of cortical inhibition. Neuron 60, 610-624.

Kallen, K., 2001. The impact of maternal smoking during pregnancy on delivery outcome. Eur. J. Public Health 11, 329-333.

Kaufman, J., Birmaher, B., Brent, D., Rao, U., Flynn, C., Moreci, P., et al., 1997. Schedule for Affective Disorders and Schizophrenia for School-Age Children-Present and Lifetime Version K-SADS-PL: initial reliability and validity data. J. Am. Acad. Child Adolesc. Psychiatry 36, 980-988.

Kaufman, J., Yang, B.Z., Douglas-Palumberi, H., Grasso, D., Lipschitz, D., Houshyar, S. Krystal, J.H., Gelernter, J., 2006. Brain-derived neurotrophic factor-5-HTTLPR gene interactions and environmental modifiers of depression in children. Biol. Psychiatry 59, 673-680.

Kim, T.S., Kim, D.J., Lee, H., Kim, Y.K., 2007. Increased plasma brain-derived neurotrophic factor levels in chronic smokers following unaided smoking cessation. Neurosci. Lett. 423, 53-57.

Lambers, D.S., Clark, K.E., 1996. The maternal and fetal physiologic effects of nicotine. Semin. Perinatol. 20, 115-126.

Lang, U.E., Sander, T., Lohoff, F.W., Hellweg, R., Bajbouj, M., Winterer, G., et al., 2007. Association of the met66 allele of brain-derived neurotrophic factor BDNF with smoking. Psychopharmacol. Berl. 190, 433-439.

Leckman, J.F., Sholomskas, D., Thompson, W.D., Belanger, A., Weissman, M.M., 1982 Best estimate of lifetime psychiatric diagnosis: a methodological study. Arch. Gen. Psychiatry 39, 879-883.

Legge, R.M., Sendi, S., Cole, J.H., Cohen-Woods, S., Costafreda, S.G., Simmons, A., et al., 2015. Modulatory effects of brain-derived neurotrophic factor Val66Met polymorphism on prefrontal regions in major depressive disorder. Br. J. Psychiatry 206, 379-384.

Lu, B., Pang, P.T., Woo, N.H., 2005. The yin and yang of neurotrophin action. Nat. Rev Neurosci. 6, 603-614.

Mannuzza, S., Fyer, A.J., Klein, D.F., Endicott, J., 1986. Schedule for Affective Disorders and Schizophrenia-Lifetime Version modified for the study of anxiety disorders SADS-LA: rationale and conceptual development. J. Psychiatr. Res 20
317-325.

Martinowich, K., Lu, B., 2008. Interaction between BDNF and serotonin: role in mood disorders. Neuropsychopharmacology 33, 73-83.

Montag, C., Basten, U., Stelzel, C., Fiebach, C.J., Reuter, M., 2008. The BDNF Val66Met polymorphism and smoking. Neurosci. Lett. 442, 30-33.

Nielsen, C.H., Larsen, A., Nielsen, A.L., 2016. DNA methylation alterations in response to prenatal exposure of maternal cigarette smoking: a persistent epigenetic impact on health from maternal lifestyle? Arch. Toxicol. 90, 231-245.

Nomura, Y., Gilman, S.E., Buka, S.L., 2011. Maternal smoking during pregnancy and risk of alcohol use disorders among adult offspring. J. Stud. Alcohol Drugs 72, 199-209.

O'Callaghan, F.V., Al Mamun, A., O'Callaghan, M., Alati, R., Najman, J.M., Williams, G. M., et al., 2009. Maternal smoking during pregnancy predicts nicotine disorder dependence or withdrawal in young adults - a birth cohort study. Aust. NZ J. Public Health 33, 371-377.

Rogers, J.M., 2009. Tobacco and pregnancy. Reprod. Toxicol.

Sakata, K., Woo, N.H., Martinowich, K., Greene, J.S., Schloesser, R.J., Shen, L., et al., 2009. Critical role of promoter IV-driven BDNF transcription in GABAergic transmission and synaptic plasticity in the prefrontal cortex. Proc. Natl. Acad. Sci. USA 106, 5942-5947.

Shin, S., Stewart, R., Ferri, C.P., Kim, J.M., Shin, I.S., Kim, S.W., et al., 2010. An investigation of associations between alcohol use disorder and polymorphisms on ALDH2, BDNF, 5-HTTLPR, and MTHFR genes in older Korean men. Int J. Geriatr. Psychiatry 25, 441-448.

Terry, M.B., Ferris, J.S., Pilsner, R., Flom, J.D., Tehranifar, P., Santella, R.M., et al., 2008 Genomic DNA methylation among women in a multiethnic New York City birth cohort. Cancer Epidemiol. Biomark. Prev.: Publ. Am. Assoc. Cancer Res. Cosponsored Am. Soc. Prev. Oncol. 17, 2306-2310.

Toledo-Rodriguez, M., Lotfipour, S., Leonard, G., Perron, M., Richer, L., Veillette, S., et al., 2010. Maternal smoking during pregnancy is associated with epigenetic modifications of the brain-derived neurotrophic factor- 6 exon in adolescent offspring. Am. J. Med. Genet. B Neuropsychiatr. Genet. 153B, 1350-1354.

Wakschlag, L.S., Pickett, K.E., Cook Jr., E., Benowitz, N.L., Leventhal, B.L., 2002. Maternal smoking during pregnancy and severe antisocial behavior in offspring: a review. Am. J. Public Health 92, 966-974.

Wang, C., Zhang, Y., Liu, B., Long, H., Yu, C., Jiang, T., 2014. Dosage effects of BDNF Val66Met polymorphism on cortical surface area and functional connectivity. J. Neurosci. 34, 2645-2651.

Weissman, M.M., Warner, V., Wickramaratne, P.J., Kandel, D.B., 1999. Maternal smoking during pregnancy and psychopathology in offspring followed to adulthood. J. Am. Acad. Child Adolesc. Psychiatry 38, 892-899.

Weissman, M.M., Wickramaratne, P., Nomura, Y., Warner, V., Pilowsky, D., Verdeli, H., 2006. Offspring of depressed parents: 20 years later. Am. J. Psychiatry 163, 1001-1008.

Weissman, M.M., Wickramaratne, P., Nomura, Y., Warner, V., Verdeli, H., Pilowsky, D.J., et al., 2005. Families at high and low risk for depression: a 3-generation study. Arch. Gen. Psychiatry 62, 29-36.

Yochum, C., Doherty-Lyon, S., Hoffman, C., Hossain, M.M., Zelikoff, J.T., Richardson, J. R., 2014. Prenatal cigarette smoke exposure causes hyperactivity and aggressive behavior: role of altered catecholamines and BDNF. Exp. Neurol. 254, 145-152.

Zeilinger, S., Kuhnel, B., Klopp, N., Baurecht, H., Kleinschmidt, A., Gieger, C., et al., 2013. Tobacco smoking leads to extensive genome-wide changes in DNA methylation. PLoS One 8, e63812. 